\title{
Cardiovascular health effects following exposure of human volunteers during fire extinction exercises
}

\author{
Maria Helena Guerra Andersen 1,2, Anne Thoustrup Saber ${ }^{2}$, Peter Bøgh Pedersen ${ }^{3}$, Steffen Loft ${ }^{1}$, \\ Åse Marie Hansen ${ }^{2,4}$, Ismo Kalevi Koponen ${ }^{2}$, Julie Elbæk Pedersen ${ }^{5}$, Niels Ebbehøj ${ }^{5}$, Eva-Carina Nørskov ${ }^{3}$, \\ Per Axel Clausen², Anne Helene Garde ${ }^{2,4}$, Ulla Vogel ${ }^{2,6}$ and Peter Møller ${ }^{1 *}$
}

\begin{abstract}
Background: Firefighters have increased risk of cardiovascular disease and of sudden death from coronary heart disease on duty while suppressing fires. This study investigated the effect of firefighting activities, using appropriate personal protective equipment (PPE), on biomarkers of cardiovascular effects in young conscripts training to become firefighters.

Methods: Healthy conscripts $(n=43)$ who participated in a rescue educational course for firefighting were enrolled in the study. The exposure period consisted of a three-day training course where the conscripts participated in various firefighting exercises in a constructed firehouse and flashover container. The subjects were instructed to extinguish fires of either wood or wood with electrical cords and mattresses. The exposure to particulate matter (PM) was assessed at various locations and personal exposure was assessed by portable PM samplers and urinary excretion of 1-hydroxypyrene. Cardiovascular measurements included microvascular function and heart rate variability (HRV).

Results: The subjects were primarily exposed to PM in bystander positions, whereas self-contained breathing apparatus effectively abolished pulmonary exposure. Firefighting training was associated with elevated urinary excretion of 1-hydroxypyrene (105\%, 95\% Cl: 52; 157\%), increased body temperature, decreased microvascular function $(-18 \%, 95 \% \mathrm{Cl}:-26 ;-9 \%)$ and altered HRV. There was no difference in cardiovascular measurements for the two types of fires.

Conclusion: Observations from this fire extinction training show that PM exposure mainly occurs in situations where firefighters removed the self-contained breathing apparatus. Altered cardiovascular disease endpoints after the firefighting exercise period were most likely due to complex effects from PM exposure, physical exhaustion and increased core body temperature.
\end{abstract}

Keywords: Cardiovascular disease, Firefighter, Ultrafine particles

\footnotetext{
* Correspondence: pemo@sund.ku.dk

${ }^{1}$ Department of Public Health, Section of Environmental Health, University of

Copenhagen, Øster Farimagsgade 5A, DK-1014 Copenhagen K, Denmark

Full list of author information is available at the end of the article
} 


\section{Background}

Firefighters have high risk of on-duty death due to cardiovascular diseases, whereas the life time risk is similar to the general population [1]. It has been shown that deaths from coronary heart disease were most frequent among firefighters who were actively engaged in suppressing fires, whereas those with non-emergency duties had the lowest mortality among on-duty firefighters [2]. The excess mortality has been attributed to various factors such as smoke, physical exhaustion, hyperthermia, dehydration and mental stress. Controlled studies of $3 \mathrm{~h}$ during fire extinction showed that firefighters had decreased left ventricular contractility and stroke volume, tachycardia and increased microvascular vasodilation within the first 30 min after cessation of the activities [3, 4]. Several studies have demonstrated that exposure to heat, associated with increased body temperature, increases the peripheral arterial compliance, shear stress and blood flow $[5,6]$. Exercise also increases the body temperature and evokes a number of hemodynamic changes, including vasodilation [7]. Above all, these results demonstrate an immediate and possibly transient effect of exercise and increased body temperature on the cardiovascular physiology.

Exposure to particulate matter (PM) from combustion of carbon-based materials such as fossil fuels is associated with increased risk of morbidity and mortality of cardiovascular diseases [8]. Firefighters may be exposed to PM when they remove their self-contained breathing apparatus while not actively engaged in fire suppression activities. Bystander exposure to smoke can therefore occur and diesel exhaust from fire trucks or pumps operated by firefighters may constitute additional sources of PM exposure. A meta-analysis of epidemiological studies has shown an inverse relationship between exposure to particulate air pollution and heart rate variability (HRV) [9]. Likewise a number of studies have documented associations between exposure to PM and cardiovascular disease endpoints such as vasomotor dysfunction and progression of atherosclerosis in animal models and humans $[10,11]$.

The chemical composition of the smoke varies substantially from one fire to another. Fires in urban settings typically give rise to very complex mixtures because of the combustion of household equipment, whereas combustion of wood can be considered as a more "clean" type of smoke. Studies on controlled exposure to wood smoke have indicated little effect on microvascular vasomotor function [12, 13], whereas HRV was decreased [14]. To the best of our knowledge, no studies have assessed biomarkers for cardiovascular disease after controlled exposure to more complex fuels than wood, such as plastic or household materials.

The aim of the present study was to assess whether firefighting activities, using appropriate personal protective equipment (PPE), were associated with cardiovascular effects in young subjects training to become firefighters. The subjects participated in smoke diving exercises to supress wood fires with or without additional items that occur in "real" fires (i.e. electrical cords and mattresses). Markers of cardiovascular function and risk factors included vasomotor function measurements by reactive hyperemia index (RHI) and cardiac autonomic nervous system regulation by HRV. Personal exposure to polycyclic aromatic hydrocarbons (PAH) was assessed by urinary excretion of 1-hydroxypyrene (1-OHP), which is a widely used biomarker of exposure to combustion products in environmental and occupational settings [15]. Biomarkers of cardiovascular risk obtained after the firefighting exercise were compared to control measurements performed 2 weeks before and 2 weeks after the firefighting course, respectively.

\section{Methods \\ Subjects}

The subjects were healthy conscripts who participated in a rescue specialist educational course, a nine-month education under the Danish Emergency Management Agency in 2015 and 2016. Self-reported pregnancy, smoking, and drug or alcohol misuse were exclusion criteria. Fifty-four subjects were enrolled in the study in four different campaigns. One female subject dropped out of the education and cardiovascular endpoints were not measured from additional 10 subjects for logistic reasons (5 subjects in each of the campaigns 3 and 4). Consequently, the final study population consisted of 32 males and 11 females. The subjects were recruited from four consecutive training classes (campaigns): campaign 1) covered 8 conscripts in the summer; 2) 11 conscripts, autumn; 3) 17 conscripts, winter; and 4) 17 conscripts, spring. Table 1 shows the characteristics of the subjects. The distribution of female subjects between campaigns varied from 17 to $36 \%$. The age of the participants varied from 18 to 26 years. Seventy-two percent of the subjects had a body mass

Table 1 Characteristics of the subjects

\begin{tabular}{llll}
\hline Characteristic & Male $(n=32)$ & Female $(n=11)$ & Total $(n=43)$ \\
\hline Age (years) & $21.0 \pm 1.3$ & $21.5 \pm 2.1$ & $21.1 \pm 1.6$ \\
Height $(\mathrm{cm})^{\mathrm{a}}$ & $181.4 \pm 6.7$ & $172.1 \pm 3.2$ & $179.0 \pm 7.2$ \\
Weight $(\mathrm{kg})^{\mathrm{a}}$ & $78.3 \pm 11.4$ & $67.6 \pm 10.0$ & $75.6 \pm 11.9$ \\
BMI $\left(\mathrm{kg} / \mathrm{m}^{2}\right)$ & $23.7 \pm 2.6$ & $22.8 \pm 3.0$ & $23.5 \pm 2.7$ \\
Subjects with & 10 & 3 & 13 \\
allergies $(\mathrm{n})^{\mathrm{a}}$ & & & $66.0 \pm 6.7$ \\
CBL.HR $(\mathrm{bpm})$ & $65.8 \pm 6.6$ & $66.9 \pm 7.4$ & 6 \\
\hline
\end{tabular}

$B M I$ body mass index, $C B L . H R$ average baseline heart rate from the two control measurements. Values are number or mean \pm SD

${ }^{\text {a }}$ Self-reported information 
index (BMI) between 18.5 and $24.9 \mathrm{~kg} / \mathrm{m}^{2}$ and $28 \%$ of the subjects had BMIs between 25 and $30 \mathrm{~kg} / \mathrm{m}^{2}$.

\section{Study protocol}

The design was a human exposure study, where the participants were studied in three exposure scenarios, serving as their own controls. In each campaign, the blood sampling and physiological measurements after each exposure scenario were conducted at the same time of the day, separated by around 14 days with the exception of campaign 3 where only 7 days separated the second and third exposure scenario due to the Christmas holiday. During the first exposure scenario, subjects were in a classroom receiving theoretical information. During the second exposure scenario, the subjects participated in a 3day smoke diving training program with various types of activities in a constructed firehouse and in a flashover container. The exercises increased in complexity as the participants acquired skills and they were wearing full PPE, including a self-contained breathing apparatus. In the third exposure scenario, the subjects were having another module component of their education unrelated to firefighting. The first and third scenarios were control measurements, whereas the second period was the exposure situation. We designed two different types of fires. The subjects supressed fires of standard wooden EUR pallets in absence (campaign 1 and 2) or presence (campaign 3 and 4) of foam mattresses and electrical cords. New material (one-third of a mattress and $2 \mathrm{~m}$ electrical cord) was added to the fires as each team of smoke divers entered the building. In total, during each day of the 3-day smokediving course, 6 mattresses and $20 \mathrm{~m}$ of electrical cords were burned. The foam mattresses were purchased in IKEA; they consisted of polyurethane $\left(28 \mathrm{~kg} / \mathrm{m}^{3}\right)$ with a cover fabric (64\% polyester and $36 \%$ cotton) and the weight of each mattress was $6 \mathrm{~kg}$. A recycling station delivered the electrical cords.

\section{Exposure assessment}

The smoke exposure was assessed with various stationary and person-borne equipment for PM measurements that measured either the particle number or mass concentrations. The supplement contains further description of the exposure setting, including type and location of PM monitors. Personal exposure to PM was assessed immediately before, during and immediately after the fire extinction exercise for 3 subjects in the first campaign. It was not possible to obtain personal PM exposure for all subjects due to a limited number of personal monitors. We therefore focussed on determining whether PM exposure occurred when the subjects were wearing PPE, including self-contained breathing apparatus. We used the urinary excretion of 1-OHP as a biomarker of PAH exposure, whereas $\mathrm{PAH}$ is used as an exposure marker of PM and smoke. The subjects delivered morning urine samples on the measurement day for the control measurements and on the day after the exposure situation. The half-life of 1$\mathrm{OHP}$ is $6-35 \mathrm{~h} \mathrm{[16],} \mathrm{thus} \mathrm{the} \mathrm{1-OHP} \mathrm{measurement} \mathrm{cap-}$ tures the exposure period, although exposures closest to the sampling contributes the most. Reverse-phase HPLC was used for the quantitative measurement of 1-OHP in urine using a previously published method [17]. We standardized for diuresis with the concentration of creatinine as used in other studies [15].

We assessed the impact of fire-related activities on the body temperature in an auxiliary experiment conducted during a smoke diving module course in 2016. The subjects performed smoke-diving exercises or acquired skills in a flashover container. Body temperature was recorded before, immediately after, and more than $20 \mathrm{~min}$ after fire-related activities using an ear thermometer (ThermoScan ${ }^{\circledR}$ 7, Braun GmbH, Kronberg, Germany). Two different activities were monitored: fire-suppression in the firehouse ( 7 to $10 \mathrm{~min}$ inside the firehouse with suppression or rescuing tasks to perform) and flashover container (30 min sitting inside a container with fire). It was not possible to organize a stringent exposure scenario due to logistic implications of the exercise, as some participants had to do fire extinction exercises several times or they hurried on to other exercises.

\section{Cardiovascular measurements}

RHI and HRV measurements were primary outcomes, which were measured non-invasively using the portable EndoPAT2000 (Itamar Medical Ltd., Israel) as previously described [18]. Briefly, finger-mountable pneumatic sensors were placed on the index fingers measuring pulse volume changes through three test stages: a baseline recording (6-7 $\mathrm{min})$, a brachial arterial occlusion of one of the arms, induced by inflation of a blood pressure cuff to a supra-systolic pressure (5 $\mathrm{min})$, and a postocclusion recording of the induced reactive hyperemia response (5 $\mathrm{min})$. Blood pressure measurements were done with a single measurement using one aneroid sphygmomanometer, before the peripheral arterial tonometry (PAT) measurement. From the baseline recording, the EndoPAT device determines the HRV based on measurement over $5 \mathrm{~min}$. The HRV results include time domain measures (SDNN, pNN50 and RMSSD), high (HF) and low frequency (LF) components as well as the LF/HF ratio. Additionally the device determines the baseline heart rate (BL.HR) and the augmentation index (AI). All the measures were done in a quiet room with the subjects resting in a seated position. The measurements in the second exposure scenario were carried out between $20 \mathrm{~min}$ to $3 \mathrm{~h}$ after cessation of the fire extinction exercise. 


\section{Statistical analysis}

We used R statistical language and the package lme4 [19] to perform a linear mixed effects analysis of the relationship between the cardiovascular endpoints and exposure. As fixed effects, we used factorial variables of exposure (before/exposure/after) and sex (male/female) and continuous variable of BMI (without interaction terms) into the model. The exposure term in the statistical analysis was either exposure period (i.e. one exposure and two non-exposure periods within each campaign) or type of fire (i.e. wood or wood with mattresses and electrical cords). Inclusion of campaign or the type of fire in the statistical analysis using the exposure period as predictor did not alter the size of the exposure-outcome relationship; thus we have reported results that have not been adjusted for effects related to campaigns. As random effects, we used by-subject intercepts. $P$-values were obtained with the function glht from multcomp [20]. The percent changes were obtained by dividing the estimate change with the intercept value from the mixed model graph line and multiplying with 100. As the RHI was expressed on a logarithmic scale, the percent change was obtained directly from the effect estimate using the expression: (exp estimate $^{-1}$ )*100. The biomarker of exposure was also analysed with the same mixed model function, using the creatinine-adjusted urinary 1-OHP concentration, sex and BMI as fixed effects. The analysis of the association between the fire extinction exercise and urinary excretion of 1-OHP demonstrated a skewed distribution of residuals. A cubic root transformation of the data and removal of one outlier did not change the statistical significance of the association; thus, we have reported the statistics of the non-transformed data. Welch t-test was used to compare the difference in means of effect change between exposed and unexposed scenarios between the different types of fire. Paired t-test was used to compare the mean body temperature difference between different exposure conditions. $P$-values $<0.05$ were considered statistically significant. Since many of the assessed biomarkers are inter-dependent, correction for multiple testing was not performed.

\section{Results}

\section{Exposure to particulate matter}

The PM exposure assessment showed that the PPE with the self-contained breathing apparatus very efficiently protected the conscripts from PM exposure by inhalation during fire-suppression activities. The mean particle number concentrations in the inhalation zone inside the selfcontained breathing apparatus during fire suppression activities were less than 1000 particles $/ \mathrm{cm}^{3}$ (Additional file 1: Table S2). We were unable to assess PM levels in the fire room, but at the floor landing above the fire extinction exercises, the total PM mass concentration was $32 \mathrm{mg} / \mathrm{m}^{3}$.
The subjects were exposed to higher particle number concentrations in situations when they were not wearing the self-contained breathing apparatus. This occurred when they received instructions or feedback at locations that were considered as "safe zones". The mean aerosol particle number concentrations in the inhalation zone varied substantially among the subjects when they were not wearing the self-contained breathing apparatus (50,000-250,000 particles $\left./ \mathrm{cm}^{3}\right)$. Further information on the exposure assessment is available in the supplemental material.

\section{Urinary excretion of 1-hydroxypyrene}

Figure 1 shows the creatinine-adjusted urinary 1-OHP concentrations in the three exposure scenarios (control measurement before, exposure and control measurement after). Results from 6 males were excluded due to missing data for the exposure measurement $(n=5)$ or for both control measurements $(n=1)$. The exposure during the fire extinction exercise increased the urinary excretion of 1 -OHP by $105 \%$ (95\% CI: 52,157\%) based on the mixed effects model. The association was especially driven by campaign 2 (Additional file 1, Figure S10).

\section{Effect of fire-suppression activity on the body temperature}

The fire extinction exercise in the firehouse increased the body temperature (average increase $=1.1^{\circ} \mathrm{C}, 95 \% \mathrm{CI}$ : $0.7,1.4, n=16, p<0.001$, paired t-test) immediately after the exercise. This was followed by an average

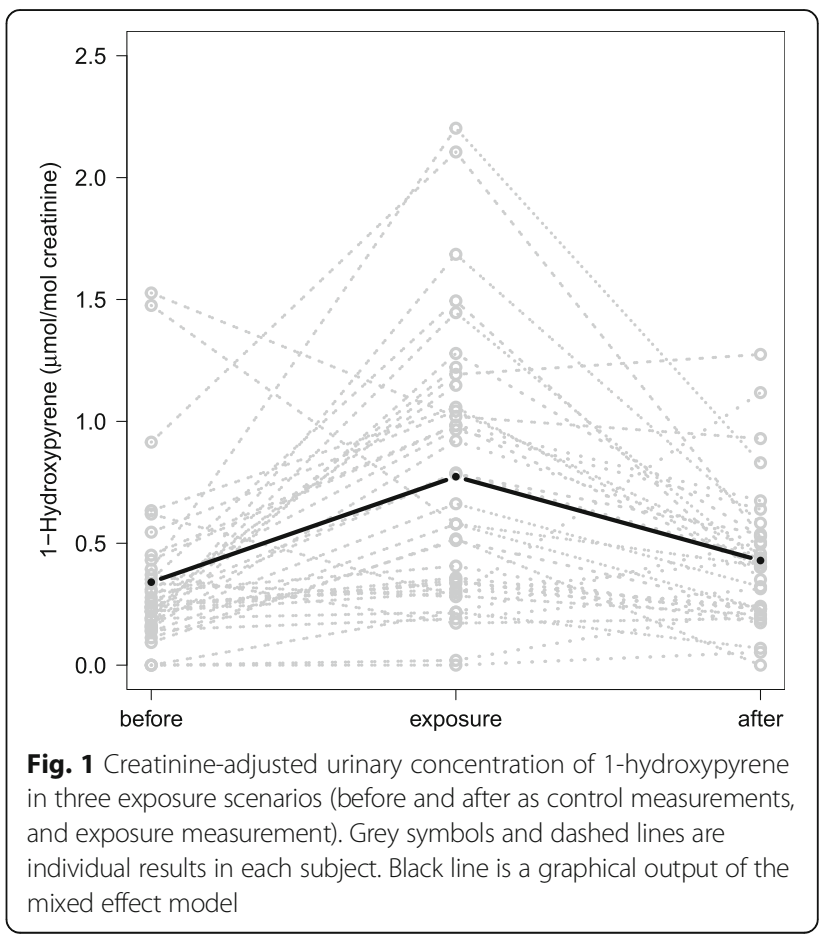


decrease of $1.6^{\circ} \mathrm{C}$ (95\% CI: $-2.0,-1.1, n=13, p<0.001$, paired $\mathrm{t}$-test), compared to the temperature immediately after the exercise, measured at $60 \mathrm{~min}$ or more after the exercise. Following the flashover container exercise, we observed an average increase of $0.8{ }^{\circ} \mathrm{C}$ (95\% CI: 0.6, 1.0, $n=8, p<0.001$, paired t-test) followed by an average decrease of $1.3{ }^{\circ} \mathrm{C}(95 \% \mathrm{CI}:-1.8,-0.8, n=7, p<0.001$, paired t-test), measured after $20 \mathrm{~min}$ and compared to the temperature immediately after the exercise. It should be noted that carryover effects cannot be ruled out as the subjects did both exercises on the same day in relatively close succession.

\section{Cardiovascular measurements}

Figure 2 presents the effect of exposure to firefighting on the cardiovascular endpoints. One female subject was eliminated from RHI analysis and one male subject was eliminated from HRV analysis, due to missing data for both control measurements. Exposure to firefighting was associated with decreased levels of RHI and time domain HRV. Table 2 presents the estimated changes for each of the cardiovascular measurements between different exposure scenarios showing a significant effect of exposure to firefighting as categorical variable on RHI, HRV both in time and frequency domains and in baseline heart rate. The mean baseline PAT signal amplitude was only modestly altered after the fire extinction exercise (change of $-0.03 \%, p<0.001)$. However adjustment for the baseline PAT signal in the statistical model did not substantially change the exposure-effect relationship of cardiovascular measurements (e.g. the percent change in RHI was decreased from $-21.9 \%$ (95\% CI: $-32.0,-10.3)$ to $-16.5 \%$ (95\% CI: -26.1, -5.6). There was no significant difference between campaigns in the exposure-effect relationship for any of the cardiovascular measurements. There were no statistically significant relationship between LnRHI and HRV measurements and urinary 1-OHP excretion (Additional file 1: Table S6). Addition of information on selfreported allergies in the statistical model did not affect the exposure-effect relationship. Outcome average results for each exposure scenario are presented in Additional file 1: Table S5.

Table 3 presents the average effect change for each of the cardiovascular endpoints between exposure and unexposed situations for the two different types of fire: wood and wood with mattresses and electrical cords. The results
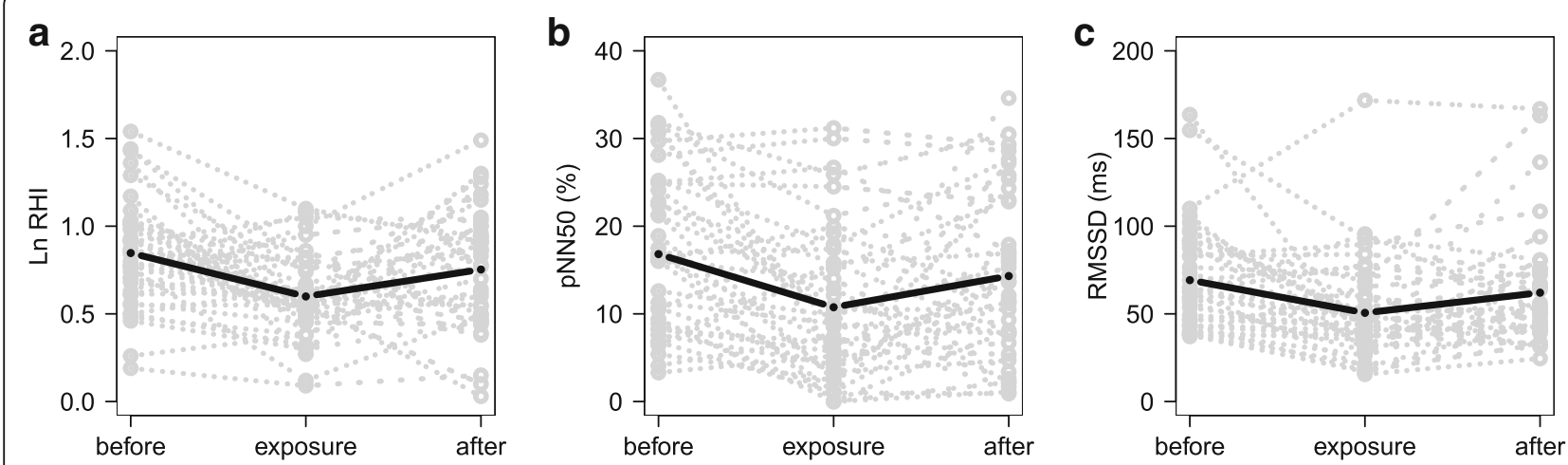

d

e
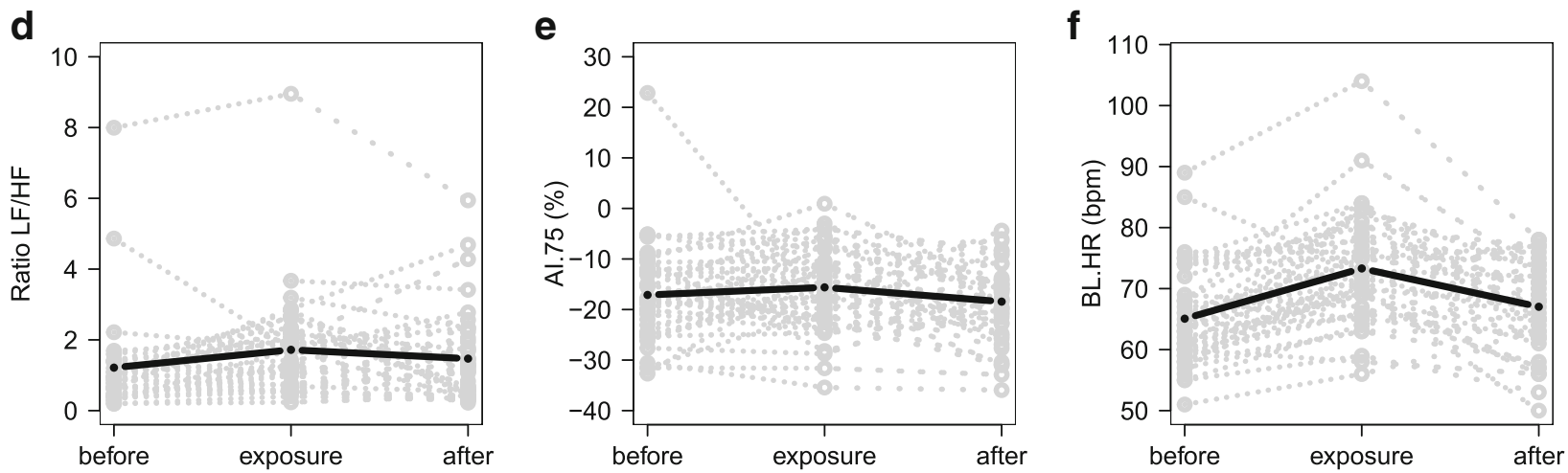

Fig. 2 Cardiovascular endpoints in the three exposure scenarios (before and after as control measurements, and exposure measurement). Natural base log of reactive hyperemia index (one subject was eliminated due to missing data in both control measurements) (a), time domain heart rate variability in pNN50 (b) and RMSSD (c), frequency domain heart rate variability $(\mathbf{d})$, augmentation index corrected for 75 bpm (e) and baseline heart rate (f). Grey symbols and dashed lines are individual results in each subject. Black line is a graphical output of the mixed effect model. pNN50, proportion of successive NN intervals differing by more than 50 milliseconds divided by total number of NN intervals; RMSSD, square root of the mean squared differences of successive NN intervals; bpm, beat per minute; ms, millisecond 
Table 2 Percent change (95\% confidence interval) in outcome levels estimated by mixed effects model adjusted for sex and body mass index

\begin{tabular}{lllll}
\hline Outcome & Exposure vs Before & Exposure vs After & After vs Before & Exposure vs Unexposed $^{a}$ \\
\hline RHI $^{\mathrm{b}}$ & $-21.9(-32.0,-10.3)^{* * *}$ & $-14.3(-25.3,-1.6)^{* *}$ & $-8.9(-20.7,4.6)$ & $-18.0(-26.0,-9.2)^{* * *}$ \\
SDNN $^{\mathrm{b}}$ & $-17.3(-28.3,-6.4)^{* *}$ & $-10.3(-21.7,1.2)$ & $-7.9(-18.9,3.1)$ & $-13.2(-22.9,-3.6)^{* *}$ \\
pNN50 $^{\mathrm{b}}$ & $-36.1(-52.3,-19.9)^{* * *}$ & $-25.1(-43.4,-6.8)^{* *}$ & $-14.7(-31.0,1.6)$ & $-28.6(-45.3,-11.8)^{* * *}$ \\
RMSSD $^{\mathrm{b}}$ & $-26.9(-41.0,-12.7)^{* * *}$ & $-18.6(-33.9,-3.4)^{*}$ & $-10.2(-24.4,4.1)$ & $-21.5(-33.4,-9.7)^{* * *}$ \\
LF $^{\mathrm{b}}$ & $27.0(11.3,42.8)^{* * *}$ & $17.8(3.7,31.9)^{*}$ & $7.8(-8.1,23.7)$ & $21.1(7.9,34.2)^{* *}$ \\
HF $^{\mathrm{b}}$ & $-15.4(-26.2,-4.7)^{* *}$ & $-4.4(-16.1,7.4)$ & $-11.6(-22.4,-0.7)^{*}$ & $-9.1(-19.2,1.0)$ \\
LF/HF $^{\mathrm{b}}$ & $41.4(15.0,67.9)^{* *}$ & $17.1(-3.9,38.2)$ & $20.7(-6.0,47.4)$ & $26.4(6.7,46.2)^{* *}$ \\
SP & $-4.4(-8.0,-0.7)^{*}$ & $-0.3(-4.2,3.5)$ & $-4.0(-7.7,-0.3)^{*}$ & $-2.4(-5.7,1.0)$ \\
DP & $-3.2(-8.6,2.3)$ & $5.8(-0.2,11.8)$ & $-8.5(-14.0,-3.0)^{* *}$ & $1.1(-3.5,5.7)$ \\
Al.75 & $-8.8(-24.8,7.3)$ & $-15.3(-30.2,-0.4)^{*}$ & $7.7(-8.3,23.8)$ & $-12.2(-26.4,2.1)$ \\
BL.HR & $12.7(9.0,16.3)^{* * *}$ & $9.4(5.8,12.9)^{* * *}$ & $3.0(-0.7,6.7)$ & $11.0(7.7,14.3)^{* * *}$ \\
\hline
\end{tabular}

$R H I$ reactive hyperemia index, SDNN standard deviation of all NN intervals, $p N N 50$ proportion of successive NN intervals differing by more than 50 milliseconds divided by total number of NN intervals, $R M S S D$ square root of the mean squared differences of successive NN intervals, $L F$ power in low frequency range (0.04$0.15 \mathrm{~Hz})$ in $\mathrm{ms}^{2}, H F$ power in high frequency range $(0.15-0.4 \mathrm{~Hz})$ in $\mathrm{ms}^{2}, L F / H F$ ratio $\mathrm{LF}\left(\mathrm{ms}^{2}\right) / \mathrm{HF}\left(\mathrm{ms}^{2}\right), S P$ systolic blood pressure $(\mathrm{mmHg}), D P$ diastolic blood pressure $(\mathrm{mmHg}), A l .75$ augmentation index corrected for $75 \mathrm{bpm}, B L . H R$ baseline heart rate (bpm)

Results are percent change from the mixed effect model in Fig. 1 except for RHI where percent change was obtained directly from the effect estimate due to the logarithmic transformation. The data are based on 43 individuals with measurements in both fire extinction exercise and control exposure condition (measurements of control exposure condition were missing for one subject in RHI and heart rate variability outcomes)

******* Significantly different $(p<0.05, p<0.01$ and $p<0.001$ respectively)

a Unexposed corresponds to the mean between "Before" and "After" for each subject

${ }^{b}$ One subject was eliminated due to missing data in both control measurements

Table 3 Within-subject effect change between exposure and unexposed situations for two different types of fires: wood pallets and wood pallets with mattresses and electrical cords

\begin{tabular}{|c|c|c|c|}
\hline Outcome & $\begin{array}{l}\text { Difference }^{a} \\
\text { with pallet fuel }\end{array}$ & $\begin{array}{l}\text { Difference }^{a} \\
\text { with mixed fuel }\end{array}$ & $\begin{array}{l}\text { Welch t-test } \\
p \text {-value }\end{array}$ \\
\hline LnRHI & $-0.1 \pm 0.3$ & $-0.3 \pm 0.3$ & 0.166 \\
\hline SDNN & $-9.3 \pm 24.9$ & $-9.8 \pm 22.2$ & 0.942 \\
\hline pNN50 & $-0.05 \pm 0.1$ & $-0.04 \pm 0.1$ & 0.879 \\
\hline RMSSD & $-14.2 \pm 29.8$ & $-14.1 \pm 22.9$ & 0.991 \\
\hline LF & $12.8 \pm 71.0$ & $56.6 \pm 74.2$ & 0.075 \\
\hline HF & $-18.7 \pm 71.0$ & $-15.1 \pm 54.7$ & 0.857 \\
\hline LF/HF & $0.2 \pm 0.7$ & $0.5 \pm 1.0$ & 0.174 \\
\hline SP & $-8.2 \pm 12.4$ & $1.6 \pm 11.8$ & 0.013 \\
\hline DP & $-3.3 \pm 7.2$ & $3.9 \pm 10.5$ & 0.012 \\
\hline Al.75 & $2.9 \pm 7.8$ & $1.6 \pm 9,1$ & 0.614 \\
\hline BL.HR & $6.2 \pm 6.7$ & $8.1 \pm 7.8$ & 0.400 \\
\hline
\end{tabular}

LnRHI natural logarithm of the reactive hyperemia index, SDNN standard deviation of all NN intervals, pNN50 proportion of successive NN intervals differing by more than 50 milliseconds divided by total number of NN intervals, RMSSD square root of the mean squared differences of successive $\mathrm{NN}$ intervals, $L F$ power in low frequency range $(0.04-0.15 \mathrm{~Hz})$ in $\mathrm{ms}^{2}, H F$ power in high frequency range $(0.15-0.4 \mathrm{~Hz})$ in $\mathrm{ms}^{2}, L F / H F$ ratio $\mathrm{LF}\left(\mathrm{ms}^{2}\right) / \mathrm{HF}\left(\mathrm{ms}^{2}\right), S P$ systolic blood pressure $(\mathrm{mmHg}), D P$ diastolic blood pressure $(\mathrm{mmHg}), A l .75$ augmentation index corrected for $75 \mathrm{bpm}, H R$ baseline heart rate (bpm). Values are mean \pm SD

${ }^{a}$ Average difference between the exposed and unexposed situations within each subject show no difference between the two different types of fire for our primary outcomes, except for blood pressure, where a statistically significant difference was observed.

\section{Discussion}

The present study showed that participation in fire extinction exercise did not cause PM exposure during firefighting using the PPE with self-contained breathing apparatus, whereas PM exposure occurred when the self-contained breathing apparatus was taken off in areas considered safe. Participation in firefight training resulted in exposure to PAHs in terms of increased urinary excretion of 1-OHP, increased body temperature and with cardiovascular risk markers in terms of both decreased microvascular function and changed HRV.

In the present study, there was no association between urinary excretion of 1-OHP and cardiovascular risk markers. Urinary excretion of 1-OHP has been established as a reliable biomarker of internal dose of PAHs in populations exposed to urban air pollution [21]. Our results demonstrate that the subjects were exposed to PAHs, although we did not appoint sources of PAHs in the present study. PAH exposure occurs both by inhalation of PM and by dermal exposure to soot [22]. Our results indicate that the exposure to $\mathrm{PAH}$ is a weak predictor of cardiovascular risk markers as compared to other risk factors such as physical exhaustion and heat. Both of these alter blood flow. Nevertheless, it should be noted that the firefighting exercises encompassed simultaneous exposure to smoke, heat and physical activity. It is not possible to separate the 
effect of smoke exposure on cardiovascular endpoints from that of heat and physical activity in the present study. It is possible that the observed short-term vascular effects predominantly reflects effects related to increased blood flow in order to ameliorate peripheral built-up of waste products from the physical exercise and reduce the core body temperature related to the last of the smoke diving exercises in the 3-day course. We did not observe any difference in the microvascular function and HRV between fires with or without mattresses and electrical cords. In parallel to the biomarkers of cardiovascular risk described in the present study, PAH exposure on skin and biomarkers of inflammation and genotoxicity in blood were assessed for the 53 study subjects [23]. Firefighting did not affect blood levels of $\mathrm{C}$-reactive protein, serum amyloid A, IL6 and IL8 concentrations, whereas there was increased level of oxidatively damaged DNA (i.e. formamidopyrimidine DNA glycosylase sensitive sites measured by the comet assay) in peripheral blood mononuclear cells compared to the mean of two control measurements performed 2 weeks before and 2 weeks after the fire fighting course [23]. The results suggest systemic oxidative stress, which is linked to cardiovascular disease.

The assessment of ambient air levels of PM indicated high concentrations inside and outside the firehouse. PM inside the firehouse came from the fire, whereas outdoor exposure represents dispersion of smoke from the firehouse and exhaust from a diesel-driven fire truck near the entrance of the firehouse. Other studies have demonstrated elevated levels of 1-OHP in subjects participating in firefighting exercises using diesel as fuel [24] and reallife fires [25]. Firefighting activities on wood fire have yielded rather low urinary levels of 1-OHP, whereas other types of urinary hydroxylated PAHs have been elevated post-exposure [26-28]. We did not obtain information on the total personal exposure to PM because of limited number of samplers and because we chose to assess PM exposure during firefighting while wearing PPE for more subjects instead of assessing whole day exposure for one or two subjects. During firefighting there was little PM inhalation exposure because the self-contained breathing apparatus was a highly efficient barrier toward particles. Pulmonary exposure was only observed when the subjects were not wearing the full PPE. The exposure assessment indicated substantial PM exposure in the areas considered safe.

We found a decreased microvascular function, measured by RHI, after the fire extinction exercise compared to the no-exposure scenario. A decreased microvascular function, using EndoPAT, has previously been described in exposure studies on air pollution particles in susceptible groups such as elderly [18, 29], whereas mixed results were reported for young and healthy subjects [30, 31]. Likewise, short-term controlled exposure studies on diesel exhaust have shown associations with reduced vasodilatory response [32]. However, short-term controlled exposure to high concentrations of wood smoke, i.e. several hundred micrograms per cubic meter, have demonstrated unaltered or even increased vasodilation response $[12,13]$. Low level of flow-mediated vasodilation corrected for shear stress is a risk factor to cardiovascular disease in firefighters; other additive risk factors are Framingham risk score and carotid intima-media thickness [33].

Altered HRV was manifested in both time and frequency domains. The fire extinction exercise was associated with decreased time domain HRV measures (SDNN, pNN50 and RMSSD), reduced high frequency components (HF), increased low frequency components (LF) and increased LF/HF ratio. Overall, it indicates an imbalance in the autonomic activation of the heart with reduced vagal activity and increased sympathetic activity. A metaanalysis has recently shown reduced measures of HRV in humans after exposure to particulate air pollution [9], whereas a review of panel studies concluded that the studies did not convincingly show inverse associations between ambient air $\mathrm{PM}_{2.5}$ concentrations and HRV [34]. Two controlled studies reported no association between short-term diesel exhaust $\left(100-300 \mu \mathrm{g} / \mathrm{m}^{3}\right.$ for $2 \mathrm{~h}$ ) and HRV $[35,36]$. However, a short-term controlled exposure to wood smoke study ( $314 \mu \mathrm{g} / \mathrm{m}^{3}$ for $3 \mathrm{~h}$ ) showed reduced HRV and increased heart rate during a 1-h post-exposure period [14]. Reduced HRV has been shown to be associated with increased risk of a first cardiovascular event in people without cardiovascular diseases [37].

Despite the demand for physical fitness, firefighters as a group seem to harbour several risk factors for cardiovascular diseases. In a recent study on young career firefighters ( $<45$ years), increased risk of sudden cardiac death was found to be largely attributed to obesity, hypertension and smoking [38]. Therefore, to avoid effect modification due to lifestyle factors, we used young and non-smoking conscripts who were generally healthy in our study. It is generally acknowledged that exposure to air pollution has an immediate effect, e.g. precipitation of myocardial infarction, and a chronic effect related to progression of atherosclerosis. Consequences of this difference in effect are apparent in the risk estimates from short-term and long-term exposure in epidemiological studies, whereas a time-integrated exposure metric suggests a monotonic exposure-effect relationship [39]. Our study is by design revealing short-term effects on both the vasculature and myocardium. The observation suggests that a reduced microvascular vasodilation response would be associated with increased peripheral resistance and progression toward hypertension and left ventricular cardiac overload due to backward failure. Indeed, HRV is reduced in patients with hypertension [40]. Increased physical workload, heat and dehydration also can be independent risk factors 
for increased risk of mortality from coronary heart disease among on-duty firefighters, whereas conditional risk factors for cardiovascular disease such as obesity, dyslipidemia, hypertension and diabetes may put certain subjects in high-risk category for sudden cardiac death.

\section{Conclusions}

In the present study, exposure of human volunteers following a 3-day firefighting training program with various types of exercises in a firehouse was associated with altered cardiovascular effects in terms of decreased microvascular function and altered HRV. The subjects were very efficiently protected against pulmonary PM exposure when using the full personal protective equipment including the self-contained breathing apparatus. Significant PM exposure was observed when the subjects took off their self-contained breathing apparatus in areas considered safe. Fire extinction exercises were associated with increased urinary 1-OHP levels indicating exposure to PAH. However, the association between urinary excretion of 1-OHP and cardiovascular effects was not statistically significant in models that included smoke exposure as categorical variable. Physical activity and heat are also conditions that occur during the fire extinction exercise, which alter blood flow. Thus, the altered cardiovascular responses after fire extinction exercises are most likely due to complex effects from PM exposure, physical exhaustion and increased core body temperature.

\section{Additional file}

Additional file 1: Supplementary material. (DOC 4338 kb)

\begin{abstract}
Abbreviations
1-OHP: 1-hydroxypyrene; Al: Augmentation index; BL.HR: Base line heart rate; BMI: Body mass index; Cl: Confidence interval; DP: Diastolic blood pressure; HF: High frequency; HPLC: High performance liquid chromatography; HRV: Heart rate variability; LF: Low frequency; PAH: Polycyclic aromatic hydrocarbons; PAT: Peripheral arterial tonometry; PM: Particulate matter; pNN50: proportion of normal-to-normal intervals differing by more than 50 miliseconds; PPE: Personal protective equipment; RHI: Reactive hyperemia index; RMSSD: Root mean square of the successive differences; SDNN: Standard deviation of normal-to-normal intervals; SP: Systolic blood pressure
\end{abstract}

\section{Acknowledgments}

The technical assistance from Anne Abildtrup, Ulla Tegner and Inge Christiansen is gratefully acknowledged. A special thanks goes to the Danish Emergency Management Agency where the measurements took place. We are also grateful to the study participants for the considerable time and willingness put into this study. We established a reference group which includes stakeholders from e.g. fire brigades, trade unions and The Danish Emergency Management Agency. We thank the reference group for involvement in the overall study design.

\section{Funding}

The research leading to these results has received funding from The Danish Working Environment Research Fund (BIOBRAND, grant 34-2014-09 / 20,140,072,567), Danish Centre for Nanosafety, grant 20,110,092,173/3 and Danish Centre for Nanosafety II).
Availability of data and materials

The datasets analysed during the current study are available from the corresponding author on reasonable request.

\section{Authors' contributions}

MHGA collected the data on vasculature effects and body temperature, assisted in the exposure measurements, analysed the results, and wrote the first draft of the manuscript. ATS designed and coordinated the study, supervised the data analysis and the writing of the manuscript. PBP measured and reported the exposure. SL designed the study and was a major contributor in the analysis and interpretation of results. AMH supervised the analysis and report of 1-OHP and was a contributor in writing the manuscript. IKK assisted in the exposure assessment. JEP collected and reported the data from the questionnaires. NE designed the study and contributed to the analysis and interpretation of results. ECN assisted in the collection of data of body temperature. PAC assisted in the exposure assessment and contributed to the writing manuscript. AHG contributed to the analysis of 1-OHP and the writing the manuscript. UV designed and supervised the study and was a major contributor in writing the manuscript. PM designed and supervised the study and was a major contributor to the analysis, interpretation and writing of the manuscript. Al authors read and approved the final manuscript.

\section{Authors' information}

Correspondence regarding this study should be addressed to UV (ubv@nrcwe.dk) or PM (pemo@sund.ku.dk).

\section{Ethics approval and consent to participate}

The Danish Committee on Health Research Ethics of the Capital Region $(\mathrm{H}-15003862)$ approved the study and study subjects participated in information meeting and provided written informed consent.

\section{Consent for publication}

Not applicable.

\section{Competing interests}

The authors declare that they have no competing interests.

\section{Publisher's Note}

Springer Nature remains neutral with regard to jurisdictional claims in published maps and institutional affiliations.

\section{Author details}

${ }^{1}$ Department of Public Health, Section of Environmental Health, University of Copenhagen, Øster Farimagsgade 5A, DK-1014 Copenhagen K, Denmark.

${ }^{2}$ The National Research Centre for the Working Environment, Lers $\varnothing$ Parkalle 105, DK-2100 Copenhagen $\varnothing$, Denmark. ${ }^{3}$ Danish Technological Institute, Teknologiparken, Kongsvang Allé 29, DK-8000 Aarhus C, Denmark. ${ }^{4}$ Department of Public Health, Section of Social Medicine, University of Copenhagen, Øster Farimagsgade 5A, DK-1014 Copenhagen K, Denmark. ${ }^{5}$ Department of Occupational and Environmental Medicine, Bispebjerg Hospital, Bispebjerg Bakke 23, DK-2400 Copenhagen, NV, Denmark. ${ }^{6}$ Department of Micro- and Nanotechnology, Technical University of Denmark, DK-2800 Kgs. Lyngby, Denmark.

Received: 29 March 2017 Accepted: 25 August 2017 Published online: 06 September 2017

\section{References}

1. Soteriades ES, Smith DL, Tsismenakis AJ, Baur DM, Kales SN. Cardiovascular disease in US firefighters: a systematic review. Cardiol Rev. 2011;19(4):202-15.

2. Kales SN, Soteriades ES, Christophi CA, Christiani DC. Emergency duties and deaths from heart disease among firefighters in the United States. N Engl J Med. 2007;356(12):1207-15.

3. Fahs CA, Yan H, Ranadive S, Rossow LM, Agiovlasitis S, Echols G, Smith D, Horn GP, Rowland T, Lane A, et al. Acute effects of firefighting on arterial stiffness and blood flow. Vasc Med. 2011;16(2):113-8.

4. Fernhall B, Fahs CA, Horn G, Rowland T, Smith D. Acute effects of firefighting on cardiac performance. Eur J Appl Physiol. 2012;112(2):735-41.

5. Carter HH, Spence AL, Atkinson CL, Pugh CJ, Naylor LH, Green DJ. Repeated core temperature elevation induces conduit artery adaptation in humans. Eur J Appl Physiol. 2014;114(4):859-65. 
6. Ganio MS, Brothers RM, Shibata S, Hastings JL, Crandall CG. Effect of passive heat stress on arterial stiffness. Exp Physiol. 2011;96(9):919-26.

7. Lefferts WK, Heffernan KS, Hultquist EM, Fehling PC, Smith DL. Vascular and central hemodynamic changes following exercise-induced heat stress. Vasc Med. 2015;20(3):222-9.

8. Brook RD, Rajagopalan S, Pope CA 3rd, Brook JR, Bhatnagar A, Diez-Roux AV, Holguin F, Hong Y, Luepker RV, Mittleman MA, et al. Particulate matter air pollution and cardiovascular disease: An update to the scientific statement from the American Heart Association. Circulation. 2010;121(21):2331-78.

9. Pieters N, Plusquin M, Cox B, Kicinski M, Vangronsveld J, Nawrot TS. An epidemiological appraisal of the association between heart rate variability and particulate air pollution: a meta-analysis. Heart. 2012;98(15):1127-35.

10. Moller P, Mikkelsen L, Vesterdal LK, Folkmann JK, Forchhammer L, Roursgaard M, Danielsen PH, Loft S. Hazard identification of particulate matter on vasomotor dysfunction and progression of atherosclerosis. Crit Rev Toxicol. 2011;41(4):339-68.

11. Moller P, Christophersen DV, Jacobsen NR, Skovmand A, Gouveia AC, Andersen MH, Kermanizadeh A, Jensen DM, Danielsen PH, Roursgaard M, et al. Atherosclerosis and vasomotor dysfunction in arteries of animals after exposure to combustion-derived particulate matter or nanomaterials. Crit Rev Toxicol. 2016:46(5):437-76.

12. Forchhammer L, Moller P, Riddervold IS, Bonlokke J, Massling A, Sigsgaard T, Loft S. Controlled human wood smoke exposure: oxidative stress, inflammation and microvascular function. Part Fibre Toxicol. 2012;9:7.

13. Hunter AL, Unosson J, Bosson JA, Langrish JP, Pourazar J, Raftis JB, Miller MR, Lucking AJ, Boman C, Nystrom R, et al. Effect of wood smoke exposure on vascular function and thrombus formation in healthy fire fighters. Part Fibre Toxicol. 2014;11:62.

14. Unosson J, Blomberg A, Sandstrom T, Muala A, Boman C, Nystrom R, Westerholm R, Mills NL, Newby DE, Langrish JP, et al. Exposure to wood smoke increases arterial stiffness and decreases heart rate variability in humans. Part Fibre Toxicol. 2013;10:20

15. Hansen AM, Mathiesen L, Pedersen M, Knudsen LE. Urinary 1-hydroxypyrene (1-HP) in environmental and occupational studies-a review. Int J Hyg Environ Health. 2008;211(5-6):471-503.

16. Jongeneelen FJ, van Leeuwen FE, Oosterink S, Anzion RB, van der Loop F, Bos RP, van Veen HG. Ambient and biological monitoring of cokeoven workers: determinants of the internal dose of polycyclic aromatic hydrocarbons. Br J Ind Med. 1990;47(7):454-61.

17. Hansen AM, Poulsen OM, Christensen JM, Hansen SH. Determination of 1hydroxypyrene in human urine by high-performance liquid chromatography. J Anal Toxicol. 1993;17(1):38-41.

18. Brauner EV, Forchhammer L, Moller P, Barregard L, Gunnarsen L, Afshari A, Wahlin P, Glasius M, Dragsted LO, Basu S, et al. Indoor particles affect vascular function in the aged: an air filtration-based intervention study. Am J Respir Crit Care Med. 2008;177(4):419-25.

19. Bates D, Machler M, Bolker BM, Walker SC. Fitting Linear Mixed-Effects Models Using Ime4. J Stat Softw. 2015;67(1):1-48.

20. Hothorn T, Bretz F, Westfall P. Simultaneous inference in general parametric models. Biom J. 2008;50(3):346-63.

21. Demetriou CA, Raaschou-Nielsen O, Loft S, Moller P, Vermeulen R, Pall $D$, Chadeau-Hyam M, Xun WW, Vineis P. Biomarkers of ambient air pollution and lung cancer: a systematic review. Occup Environ Med. 2012;69(9):619-27.

22. IARC. Painting, firefighting, and shiftwork. In: Monographs on the Evaluation of the Carcinogenic Risks to Humans vol 98. Edited by International Agency for Research on Cancer, vol. 98; 2010: 9-764.

23. Andersen MH, Saber AT, Clausen PA, Pedersen JE, Lohr M, Kermanizadeh A, Loft S, Ebbehoj N, Hansen AM, Pedersen PB, et al. Association between polycyclic aromatic hydrocarbons exposure and peripheral blood mononuclear cell DNA damage in human volunteers during fire extinction exercises. Mutagenesis. 2017; in press

24. Moen BE, Ovrebo S. Assessment of exposure to polycyclic aromatic hydrocarbons during firefighting by measurement of urinary 1 hydroxypyrene. J Occup Environ Med. 1997;39(6):515-9.

25. Caux C, O'Brien C, Viau C. Determination of firefighter exposure to polycyclic aromatic hydrocarbons and benzene during fire fighting using measurement of biological indicators. Appl Occup Environ Hyg. 2002;17(5):379-86

26. Fernando S, Shaw L, Shaw D, Gallea M, VandenEnden L, House R, Verma DK, Britz-McKibbin P, McCarry BE. Evaluation of Firefighter Exposure to Wood
Smoke during Training Exercises at Burn Houses. Environ Sci Technol. 2016;50(3):1536-43.

27. Oliveira M, Slezakova K, Alves MJ, Fernandes A, Teixeira JP, Delerue-Matos C, Pereira MD, Morais S. Firefighters' exposure biomonitoring: Impact of firefighting activities on levels of urinary monohydroxyl metabolites. Int J Hyg Environ Health. 2016;219(8):857-66.

28. Robinson MS, Anthony TR, Littau SR, Herckes P, Nelson X, Poplin GS, Burgess JL. Occupational PAH exposures during prescribed pile burns. Ann Occup Hyg. 2008;52(6):497-508.

29. Hemmingsen JG, Rissler J, Lykkesfeldt J, Sallsten G, Kristiansen J, Moller PP, Loft $\mathrm{S}$. Controlled exposure to particulate matter from urban street air is associated with decreased vasodilation and heart rate variability in overweight and older adults. Part Fibre Toxicol. 2015;12:6.

30. Brauner EV, Moller P, Barregard L, Dragsted LO, Glasius M, Wahlin P, Vinzents $P$, Raaschou-Nielsen O, Loft S. Exposure to ambient concentrations of particulate air pollution does not influence vascular function or inflammatory pathways in young healthy individuals. Part Fibre Toxicol. 2008:5:13.

31. Weichenthal S, Hatzopoulou M, Goldberg MS. Exposure to traffic-related air pollution during physical activity and acute changes in blood pressure, autonomic and micro-vascular function in women: a cross-over study. Part Fibre Toxicol. 2014;11:70.

32. Barath $\mathrm{S}$, Mills $\mathrm{NL}$, Lundback $M$, Tornqvist $H$, Lucking AJ, Langrish JP, Soderberg S, Boman C, Westerholm R, Londahl J, et al. Impaired vascular function after exposure to diesel exhaust generated at urban transient running conditions. Part Fibre Toxicol. 2010;7:19.

33. Anderson TJ, Charbonneau F, Title LM, Buithieu J, Rose MS, Conradson $\mathrm{H}$, Hildebrand K, Fung M, Verma S, Lonn EM. Microvascular function predicts cardiovascular events in primary prevention: long-term results from the Firefighters and Their Endothelium (FATE) study. Circulation. 2011;123(2):163-9.

34. Buteau S, Goldberg MS. A structured review of panel studies used to investigate associations between ambient air pollution and heart rate variability. Environ Res. 2016;148:207-47.

35. Peretz A, Kaufman JD, Trenga CA, Allen J, Carlsten C, Aulet MR, Adar SD, Sullivan $\mathrm{JH}$. Effects of diesel exhaust inhalation on heart rate variability in human volunteers. Environ Res. 2008;107(2):178-84.

36. Tong H, Rappold AG, Caughey M, Hinderliter AL, Graff DW, Berntsen JH, Cascio WE, Devlin RB, Samet JM. Cardiovascular effects caused by increasing concentrations of diesel exhaust in middle-aged healthy GSTM1 null human volunteers. Inhal Toxicol. 2014;26(6):319-26.

37. Hillebrand S, Gast KB, de Mutsert R, Swenne CA, Jukema JW, Middeldorp S, Rosendaal FR, Dekkers OM. Heart rate variability and first cardiovascular event in populations without known cardiovascular disease: meta-analysis and dose-response meta-regression. Europace. 2013;15(5):742-9.

38. Yang J, Teehan D, Farioli A, Baur DM, Smith D, Kales SN. Sudden cardiac death among firefighters $</=45$ years of age in the United States. Am J Cardiol. 2013;112(12):1962-7.

39. Pope CA 3rd. Mortality effects of longer term exposures to fine particulate air pollution: review of recent epidemiological evidence. Inhal Toxicol. 2007; 19(Suppl 1):33-8.

40. Singh JP, Larson MG, Tsuji H, Evans JC, O'Donnell CJ, Levy D. Reduced heart rate variability and new-onset hypertension: insights into pathogenesis of hypertension: the Framingham Heart Study. Hypertension. 1998;32(2):293-7.

\section{Submit your next manuscript to BioMed Central and we will help you at every step:}

- We accept pre-submission inquiries

- Our selector tool helps you to find the most relevant journal

- We provide round the clock customer support

- Convenient online submission

- Thorough peer review

- Inclusion in PubMed and all major indexing services

- Maximum visibility for your research

Submit your manuscript at www.biomedcentral.com/submit 